\title{
¿De asalariados rurales a...? Acceso a la tierra en el norte uruguayo
}

\author{
Gabriel Oyhantcabal Benelli \\ Universidad de la República, Uruguay. \\ gaboyha@gmail.com
}

Cita sugerida: Oyhantcabal Benelli, G. (2018). ¿De asalariados rurales a...? Acceso a la tierra en el norte uruguayo. Mundo Agrario, 19 (40), e076. https://doi.org/10.24215/15155994e076

Recibido: 15 de julio de 2016 - Aceptado: 05 de febrero de 2018 - Publicado: 26 de marzo de 2018 http://creativecommons.org/licenses/by-nc-sa/4.0/deed.es_AR 


\section{¿De asalariados rurales a...? Acceso a la tierra en el norte uruguayo}

From rural wage workers to...? Land access in the Uruguayan north

Gabriel Oyhantcabal Benelli

Universidad de la República, Uruguay

gaboyha@gmail.com

\section{Resumen:}

Desde 2006 el proyecto sucroalcoholero en Bella Unión, Uruguay, dinamizó diversas experiencias de acceso a tierra por parte de asalariados rurales organizados. Este artículo analiza el caso de los trabajadores de la Unión de Trabajadores Azucareros de Artigas en la Colonia Sendic con foco en los cambios en la subsunción del trabajo en el capital. Los resultados muestran que los colonos conforman una clase híbrida que oficia de intermediaria entre la fuerza de trabajo y el capital, resultado de la imposibilidad de recrear al productor mercantil dada la forma en que se valoriza el capital en el complejo sucroalcoholero.

Palabras Clave: Subsunción en el capital, Diferenciación social, Políticas de tierra, Asalariados rurales, Uruguay.

\section{ABstract:}

From 2006 the sugar-ethanol project in Bella Unión, Uruguay, produced different land access experiences by unionised rural wage workers. This article analyses the case of the workers from the "Unión de Trabajadores Azucareros de Artigas" in the Colonia Sendic focused on the changes in the subsumption of labour under capital. The results show that the settlers constitute a hybrid class, which intermediates between labour force and capital, as a result of the impossibility to recreate the petty commodity producer by the specific form of capital valorization in the sugar-ethanol complex.

KEYWORDS: Subsumption under capital, Social differentiation, Land policy access, Rural wage workers, Uruguay.

\section{INTRODUCCIÓN}

Durante la historia agraria del Uruguay los asalariados rurales no aparecieron en los procesos de restructuración agraria, sino que solamente fueron parte de las reconfiguraciones del mercado de trabajo. En la estructura social agraria el asalariado rural aparece como clase desde la relación salarial y no como clase vinculada al acceso a la tierra, lo que explica en buena medida su ausencia en el debate sobre la cuestión de la tierra (Oyhantçabal y Carámbula, 2011).

No obstante este escenario general, las luchas de los asalariados rurales de la caña de azúcar organizados en la Unión de Trabajadores Azucareros de Artigas (UTAA) muestran un caso donde la reivindicación del acceso a la tierra ha sido y es una de las pautas centrales de su accionar, junto con las reivindicaciones más estrictamente sindicales (salario, condiciones de trabajo, etc.). La lucha por la tierra es una consigna ligada a la UTAA desde su fundación en 1961 que ha pasado por distintas etapas a lo largo de la historia (Moraes, 2012), pero que recién se traduce en experiencias significativas de acceso a la tierra luego de intensas movilizaciones en el marco de la llegada al gobierno del Frente Amplio (FA) en 2005. En este nuevo escenario, el FA impulsa el denominado proyecto sucroalcoholero a través de la empresa ALURSA (Alcoholes del Uruguay), que relanzó la producción de caña de azúcar en Bella Unión, y reactivó el Instituto Nacional de Colonización (INC) -un ente público cuyo cometido es la distribución de la tierra- luego de casi 30 años de inacción (Toledo, 2014).

Entre estas experiencias, la Colonia Raúl Sendic Antonaccio (CRSA), creada en 2010 por el INC para colaborar con el incremento del área cañera para el proyecto sucro-alcoholero, ha sido la más relevante, por el área total colonizada con 2.033 ha, y por la cantidad de trabajadores beneficiados, con 52 adjudicatarios organizados en seis grupos bajo modalidad asociativa. De los seis grupos, cuatro se conformaron por 
adjudicación directa de las fracciones de tierras a organizaciones de trabajadores de Bella Unión, entre otras la UTAA, que aportó 11 trabajadores asalariados (Echeverriborda et al., 2014).

Este proyecto configura un caso relativamente novedoso en el país, en la medida en que han sido escasas las experiencias de acceso a la tierra por parte de asalariados rurales sindicalizados, y en particular integrantes del sindicato rural que históricamente planteó la cuestión del acceso a la tierra en Uruguay. Más cuando ocurre en el marco de un contexto nacional profundamente adverso para los productores mercantiles no-capitalistas (en general definidos como productores familiares) en franco retroceso de la estructura agraria nacional desde 1960 (Piñeiro y Cardeillac, 2014).

Estas experiencias de acceso a la tierra por parte de trabajadores "sin tierra" pueden entenderse como contradictorias con la tendencia a la diferenciación social (Foladori, 1986) típica de las sociedades capitalistas, que separa, y no reúne, a los productores directos de los medios de producción. Hocsman (2003) las denomina procesos de recreación campesina. En estos procesos el propio capital, según el contexto históricoespacial, reproduce unidades de producción no-capitalistas en las que el trabajo se subsume de forma híbrida en el capital (Marx, 2012) ${ }^{1}$ con el objetivo de apropiar plusvalor y producir fuerza de trabajo latente en el campo. Mientras que Oliveira (2004) ubica estos procesos como parte del desarrollo combinado y contradictorio del capitalismo que, al tiempo que reproduce formas de subsunción formal y real del trabajo en el capital, reproduce contradictoriamente formas de subsunción híbrida que subordinan al productor directo de mercancías al proceso de valorización.

La literatura reciente sobre este nuevo período en la historia social y agraria ha abordado la movilización social, la situación de los trabajadores y la lucha por la tierra (Otero, 2011; Panizza, 2012; Pereira, 2011; Sarachu et al., 2013; Silva, 2015). En el caso de las experiencias de acceso a tierra, destacan los trabajos de Moraes (2012) sobre "Campo Placeres" -la primer experiencia de acceso a tierra impulsada en 2006 por ALUR-, y de Chiappe y Espasandín (2014) sobre la constitución y los conflictos en el proceso de creación de la CRSA. También existen investigaciones a nivel nacional sobre experiencias de acceso a tierra por parte de asalariados de diversos rubros con foco en los procesos asociativos (Toledo, 2014).

No obstante, y con excepción del trabajo de Moraes (2012), la literatura no ha abordado los cambios en las formas de subsunción en el capital que produce el pasaje de asalariado a colono-productor mercantil, sus impactos sobre la conciencia de clase, entendida como la representación consciente de las relaciones que objetivamente se establecen en la producción, y cómo se insertan estos procesos en la tendencia global a la diferenciación social de los productores mercantiles.

Este artículo se propone aportar conocimiento sobre las características del proceso de pasaje de asalariados a productores-colonos a partir del caso de los trabajadores de la UTAA que ingresaron a la CRSA en el período 2010-2012. Para esto se propone responder las siguientes preguntas: (1) ¿hay un cambio de clase en el proceso de pasaje de asalariado a colono-productor?, y de haberlo, ¿qué características adquiere?; (2) ¿cómo impacta este cambio en su conciencia de clase?, y (3) ¿cómo se inscribe el proceso de colonización en el marco del proceso general de diferenciación social en el campo uruguayo?

Para la investigación se utilizaron tres técnicas para la producción de datos: entrevistas semiestructuradas y observación participante para la producción de datos primarios, y análisis documental de información secundaria, fundamentalmente actas del directorio del INC y apuntes de campo del autor resultantes de su trabajo como extensionista en la zona entre 2008 y 2012. Durante el segundo semestre de 2012 fueron entrevistados ocho colonos de la conformación inicial del grupo y tres informantes calificados, seleccionados en función de su conocimiento directo de la experiencia. Con ambos tipos de entrevistados se utilizó un formulario semiestructurado específico. Las entrevistas fueron grabadas con previa autorización del entrevistado para su posterior desgrabación y análisis. Asimismo se participó en cuatro jornadas de trabajo completas durante la zafra de la caña 2012 sin asumir tareas laborales.

Además de esta introducción, el artículo aborda en un segundo apartado las características del complejo sucroalcoholero en Bella Unión, los principales rasgos de la CRSA y del grupo de asalariados de la UTAA 
que accedió a ésta. En un tercer apartado se analizan las transformaciones que acarreó la transformación de los asalariados en colonos. En el cuarto apartado se discuten las principales preguntas de esta investigación, referidas al cambio de posición y conciencia de clase, y a las particularidades del proceso de diferenciación social en el complejo sucroalcoholero. El quinto apartado presenta las principales conclusiones del artículo.

\section{El COMPlejo SUCRO-ALCOHOLERo y EL ACCESO A LA TIERRA EN BELLA UNión}

\subsection{Alcoholes del Uruguay SA}

Bella Unión es conocida en Uruguay fundamentalmente porque de 1940 a la fecha es prácticamente el único territorio donde se produce caña de azúcar. El impulso a la producción e industrialización de caña para obtener azúcar refinada tiene su origen en el marco del período de industrialización por sustitución de importaciones (1946-1959). Este proceso consolidará a dos sujetos centrales de los últimos 60 años de historia local: los "cañeros" - plantadores de caña herederos de la tradición agrícola de la zona, también conocidos como los "gringos"-, y los "peludos" 2 el proletariado agrícola que se instala en la zona ante la demanda de fuerza de trabajo para el nuevo cultivo (Moraes, 1990).

La agroindustria azucarera pasará por varias etapas en su historia, desde el impulso inicial, una primera crisis en la década del 60, el polo de desarrollo impulsado durante la dictadura militar (1973-1985) que hará del ingenio azucarero de la Cooperativa Agraria Limitada Norte Uruguayo (CALNU) el eje del proyecto, la segunda crisis dinamizada por la implementación del neoliberalismo (1992-2005), y finalmente la reactivación de la producción de caña en el marco de la llegada del FA al gobierno (2005) que impulsó el denominado proyecto sucroalcoholero. El FA creó la empresa Alcoholes del Uruguay SA (ALUR SA) de propiedad estatal pero en la égida del derecho privado. Sus accionistas iniciales fueron la empresa estatal de combustibles, ANCAP, con el 90 \% de las acciones, y la Corporación Nacional de Desarrollo con el 10 \%, que luego vendió sus acciones a la petrolera estatal venezolana, PDVSA (Echeverriborda et al., 2014). Según Moraes (2012), los objetivos del nuevo gobierno con ALUR incluyeron: la generación de empleo, la utilización de recursos y capacidad instalada en la zona, la producción de azúcar con materia prima nacional, garantizar la producción de combustible (etanol) en el marco de la diversificación de la matriz energética, y la generación de energía eléctrica para el proceso industrial y la venta del excedente.

Para la promoción de la caña de azúcar ALUR favoreció una intensa integración del complejo agroindustrial, financiando el cultivo y la asistencia técnica, lo que permitió llevar el área cañera de 3.000 a 9.500 ha entre 2006 y 2014. La expansión del área se dio en tierras de privados, de cañeros que expandieron su área e incluso en campos antes destinados al arroz, y en tierras públicas, en particular mediante tres iniciativas: "Campo Placeres", arrendado por ALUR y distribuido entre 39 trabajadores en 2006 (Moraes, 2012), la CRSA creada por el INC en 2010 y la Colonia Eliseo Salvador Porta creada por el INC en 2014.

La nueva etapa que abrió el proyecto ALUR configuró el complejo sucroalcoholero, que desde la perspectiva de los complejos agroindustriales (Buxedas, 1984) puede ser analizado en cuatro fases productivas: la preagrícola, la agrícola, la industrial y la comercial. En la fase preagrícola se ubican los agentes que proveen los insumos para la producción de caña (fertilizantes, herbicidas, maquinaria, agua). En esta fase destacan proveedores de insumos y concesionarios de maquinaria, entre los cuales tiene especial relevancia ALUR, principal distribuidora y financiadora de insumos. En esta fase también destacan los sistemas de riego que proveen de agua a los productores de caña que, en el caso de los sistemas de riego CALPICA y CALAGUA, son controlados por los principales productores de caña y presentan mayores tarifas.

La fase agrícola se organiza en torno a la producción de caña de azúcar para el ingenio. En 2009 la producción de caña la realizaron 215 establecimientos, de los cuales 156 eran productores individuales y 59 grupales, con una importante heterogeneidad en relación a la superficie controlada (Sarachu et al., 2013). 
Entre los productores de caña se encuentran pequeños productores que utilizan mano de obra familiar complementada con trabajo asalariado, grandes empresarios que contratan a la gran mayoría de los 1.200 asalariados y controlan la mayor parte del área de caña, y el propio ALUR, que produce caña en campos arrendados y realiza tareas productivas en predios de otros productores. ALUR también se hace presente en la fase agrícola a través de sus técnicos que asesoran y supervisan de forma gratuita a los productores que reciben insumos y financiamiento de la empresa.

La fase industrial del complejo es desarrollada exclusivamente por ALUR, en tanto posee el único ingenio en el país que compra y procesa caña de azúcar, lo que lo vuelve un monopsonio (único comprador). Inicialmente el ingenio se dedicó exclusivamente a la producción de azúcar, pero con la inauguración de la destilería en el año 2010 comenzó la producción de etanol, y con la inauguración de la nueva caldera comenzaron a vender remanentes de energía eléctrica. En el ingenio trabajan alrededor de 600 obreros durante la zafra (Otero, 2011).

La fase la comercial incluye las tareas de acopio, distribución y comercialización de los productos elaborados en el ingenio. En el caso del azúcar la comercialización está bajo control directo de ALUR que se encarga de su distribución en todo el país. En lo que refiere a la distribución y venta del etanol, esta tarea es realizada por la empresa CABA SA, perteneciente al grupo ANCAP (Echeverriborda et al., 2014).

ALUR desarrolla una estrategia orientada a la integración vertical de todo el complejo; incide e intenta direccionar todas sus fases, lo que supone un proceso tendiente a la monopolización del territorio (Oliveira, 2004) para apropiar el plusvalor generado por productores directos (que utilizan su propia fuerza de trabajo) o bajo relaciones salariales, en cuyo caso la disputa es con los empresarios cañeros. La efectivización de la monopolización del territorio incluye entre otros mecanismos: la definición del precio de la caña de azúcar, el financiamiento de todas las fases del cultivo, el suministro de insumos, la presencia de un equipo de técnicos que asesora y controla/supervisa la producción de caña de azúcar, el control relativo del precio final del azúcar, el control del precio final del etanol en tanto el precio lo fija la empresa estatal ANCAP, el control de la comercialización del azúcar y del etanol, y el financiamiento de la compra de maquinaria e infraestructura para los proveedores de servicios locales (Echeverriborda et al., 2014).

\subsection{La Colonia Raúl Sendic Antonaccio}

La CRSA, ubicada en el departamento de Artigas, $30 \mathrm{~km}$ al sur de la ciudad de Bella Unión se creó con la compra por parte del Instituto Nacional de Colonización de un campo de 2.033 hectáreas por una suma cercana a los US\$ 6 millones para "promover los emprendimientos asociativos y favorecer el pasaje del asalariado rural del cultivo de caña de azúcar a productor" (INC, 2009, p. 1), y al mismo tiempo fomentar la producción de caña de azúcar para abastecer al ingenio de ALUR. La CRSA es una colonia dirigida según lo establecido por el artículo $7^{\circ}$ inciso $10^{\circ}$ de la Ley 11.029, de forma que los colonos deben producir caña.

La colonia se dividió en 6 fracciones de forma que tuvieran similar superficie sembrable con caña de azúcar. Inicialmente se proyectaba sembrar el $80 \%$ de la superficie con caña ( 1.600 ha) destinando el $20 \%$ restante (400 ha) para la diversificación productiva. A cada una de las fracciones ingresó en febrero de 2010 un grupo de entre 7 y 11 trabajadores bajo la modalidad de arrendamiento en disfrute precario con una duración de dos años, para producir en forma colectiva. La definición del número de integrantes por fracción tomó como supuesto que un emprendimiento cañero con rubros de diversificación productiva es rentable para el sustento de una familia a partir de 35 ha en producción (INC, 2009).

El período de definición de los aspirantes estuvo marcado por intensas y conflictivas negociaciones entre el INC y las organizaciones de asalariados UTAA, SOCA (Sindicato de Obreros de la Caña de Azúcar) y SUCAL (Sindicato Único de Calagua), y las organizaciones de productores familiares APAARBU (Asociación de Pequeños Agricultores y Asalariados Rurales de Bella Unión) y Gremial Granjera, que finalmente se integrarán a la CRSA. La negociación se dilató porque mientras las organizaciones exigían 
que todos los colonos provinieran de sus miembros, el INC proponía que sólo un tercio proviniera de las organizaciones. Finalmente, se acordó que cuatro de las seis fracciones se adjudicaran directamente a grupos de aspirantes seleccionados por las organizaciones, y las dos restantes se adjudicaran a través de un llamado abierto (resolución del INC del 19/08/2009).

El criterio para la selección de los colonos de las organizaciones implicó que éstas propusieran candidatos con posterior aprobación del directorio del Instituto. Según el INC (2009), los criterios establecidos fueron: asalariados rurales con experiencia de por lo menos tres años en el cultivo de caña de azúcar, dispuestos a integrarse en un grupo de producción; grupos de asalariados rurales con experiencia de por lo menos tres años en el cultivo de caña de azúcar e historia de funcionamiento grupal; pequeños productores cañeros, con superficie de cultivo propio no mayor de 15 has con tres años de entrada de caña en el ingenio dispuestos a integrarse en un grupo de producción; hijos de pequeños productores cañeros con experiencia de por lo menos tres años en el cultivo de caña de azúcar, y la posibilidad de considerar situaciones de pequeños productores cañeros con núcleos familiares numerosos cuyos miembros se encuentren en edad de trabajar.

La adjudicación de la tierra a los colonos se efectivizó en febrero de 2010, pero las actividades productivas en el campo comenzaron a fines de 2008, luego de un acuerdo entre el INC y ALUR para que este último comenzara con la siembra de caña empleando mano de obra asalariada, que en muchos casos fue provista por los futuros colonos. De esta forma, los grupos ingresaron a un campo con buena parte de la caña sembrada (más de 500 has), lo que los obligó a asumir una deuda con el INC y ALUR al momento de firmar el contrato de adjudicación. Además de la deuda, las condiciones de ingreso implicaron un período de prueba (disfrute precario) de dos años en el que no estuvieron establecidos de antemano los criterios para la evaluación, la ausencia de condiciones para la radicación de las familias, y la falta de recursos financieros suficientes para las inversiones necesarias (transporte, maquinaria, infraestructura, diversificación), aspectos que quedaron en manos de ALUR.

En lo relativo a la radicación, los colonos ingresaron a la CRSA sin colonizarla, lo que se explica por la falta de una política de radicación explícita por parte del INC, en la medida en que es posible desarrollar la actividad productiva viviendo en Bella Unión, y porque no todos los colonos tienen la voluntad de radicarse; muchos prefieren mantener separado el espacio productivo del reproductivo.

Las características de las familias de los colonos al ingresar a la Colonia están sintetizadas en el censo de población realizado por Toledo (2011). La población de la CRSA incluye 48 hogares y 220 personas, con un promedio de 5 personas por hogar, de las cuales 120 son hombres y 100 mujeres. La edad promedio era de 24 años y la mitad de la población tenía 18 años o menos. El 62,7 \% de la población estaba en edad de trabajar (138 personas), de las cuales el 64,5\% era activa económicamente ( 89 personas). Sin embargo, como las familias no están radicadas en el campo, las cifras totales no refieren a la población que vive en la CRSA, sino a las familias de los colonos que viven en Bella Unión. En promedio los hogares recibían antes de ingresar a la Colonia por concepto de los diversos ingresos un monto total de unos US\$ 820 mensuales, unos US\$ 200 per cápita, cifra que indicaba que el $79 \%$ de los hogares y el $85 \%$ de las personas se encontraban en 2010 por debajo de la línea de pobreza para el interior del país. Según consigna el Censo, en ese año el conjunto de hogares tendría que haber incrementado un $65 \%$ sus ingresos monetarios mensuales para salir de la pobreza.

Toledo (2011) caracteriza a las familias de colonos en tres estratos: asalariados predominantemente zafrales sin especialización; asalariados de carácter más permanente con algún grado de especialización, y pequeños productores familiares hortícola-cañeros. El primer estrato representa fundamentalmente a los asalariados de la caña. Es el estrato mayoritario que abarca el $50 \%$ (24) de los hogares, con todos los hogares bajo la línea de pobreza y varios cercanos a la línea de indigencia. 


\subsection{El grupo Peludos del Norte}

Los once trabajadores provenientes de la UTAA conformaron el grupo "Peludos del Norte". El mismo se integró a partir de una lista de aspirantes elaborada por el sindicato con aquellos afiliados que más activamente participaron de su comisión de tierras y que manifestaron su intención de ingresar a la CRSA; a ellos se sumaron tres trabajadores que habían ingresado a "Campo Placeres" en 2006.

Todos los integrantes del grupo se ubican dentro del estrato asalariados predominantemente zafrales sin especialización propuesto por Toledo (2011), lo que da cuenta de su condición de cortadores de caña zafrales, con niveles de ingreso per cápita promedio por debajo de la línea de la pobreza, bajos niveles de educación formal y capacitación. Entre los 11 integrantes, con edades entre los 30 y los 50 años, había solo dos mujeres titulares, y una de ellas delegaba las tareas productivas en su pareja.

Las trayectorias laborales de todos los integrantes están marcadas por el trabajo rural zafral desde jóvenes (después de los 13 años), en especial en la caña, pero con trabajos eventuales en otros rubros, en muchos casos combinados con trabajo zafral en la construcción en Montevideo y Maldonado, especialmente durante el período de crisis de la industria azucarera (década del 90), en una estrategia que combinaba corte de caña en invierno e industria de la construcción en verano. El perfil predominante de las familias, muestra un número de integrantes por encima del promedio nacional, padres y hermanos que también fueron/son en muchos casos cortadores de caña en Bella Unión, varios vinculados a la UTAA, y madres dedicadas sobre todo a tareas domésticas. Al ingresar a la CRSA, era el grupo con más integrantes ( 70 personas), de los cuales 41 eran hombres y 29 mujeres, y con más integrantes jóvenes (77\% con menos de 29 años en 2010).

El grupo no tenía trayectoria previa como colectivo de trabajo, aunque algunos de sus integrantes sí tenían trayectorias comunes, hecho que es relevante destacar. En particular se identifican cuatro tipos de trayectorias en común. La primera, y una de las más influyentes, es el parentesco: de los 11 titulares, tres son hermanos entre sí y otros dos también son hermanos entre sí. La segunda está vinculada con el origen común de tres titulares que llegaron a la CRSA desde "Campo Placeres", a donde habían ingresado en 2006 gracias a su condición de dirigentes de UTAA (Moraes, 2012). La tercer trayectoria, la más evidente quizás, está dada por la condición de militante/afiliado a la UTAA, lo que marca un origen y una identidad común. No obstante este elemento en común, no todos los titulares tuvieron el mismo nivel de involucramiento con el sindicato, habiendo desde dirigentes y militantes de la comisión de tierras, hasta trabajadores con un vínculo más débil, que vieron en el sindicato una vía de acceso a la tierra principalmente. Por último, algunos trabajadores tuvieron una trayectoria común como asalariados en los trabajos de preparación y siembra de caña en la CRSA antes de la adjudicación.

La escasa experiencia grupal y las diversas trayectorias han condicionado su devenir, siendo uno de los grupos que más cambios sufrió desde su conformación. El grupo se fraccionó en dos, apenas seis meses después de su ingreso, lo que originó "Peludos del Norte 1", con 6 titulares, y "Peludos del Norte 2", con 5 titulares. Este fraccionamiento fue posteriormente aprobado por el INC. La división fue resultado de la interacción de varios factores, aunque se encuentran algunos elementos centrales relacionados con las trayectorias comunes antes mencionadas.

La división no fue el único cambio que experimentó el grupo. En Peludos del Norte 2, a fines de 2011 es expulsado uno de sus integrantes, que no era el colono titular sino que representaba a su compañera, y que luego de gestiones realizadas por el INC fue aceptado en otro de los grupos de la CRSA. Esta situación obliga al grupo a incorporar otro integrante. Por su parte, Peludos del Norte 1 tiene a comienzos de 2012 una subdivisión en tres subgrupos, uno de tres integrantes, otro de dos y el último individual. Esta división no fue aceptada por el INC, pero se operativizó por la vía de los hechos en tanto ALUR le abrió a cada subfracción una cuenta personalizada para el financiamiento y el suministro de insumos. El patrón central de este segundo reagrupamiento fue el parentesco. 


\section{LA INSERCIÓN DE LOS NUEVOS COLONOS EN EL COMPLEJO SUCROALCOHOLERO}

El ingreso a la CRSA supuso para los colonos una reinserción en el complejo sucroalcoholero, en la medida en que dejaron de vender su fuerza de trabajo y pasaron a gestionar emprendimientos productivos. Para su mejor comprensión se analizan los cambios que produjo el acceso a la tierra, las nuevas formas de subordinación que experimentan y los márgenes de autonomía que permite la nueva inserción, y por último, su rol como compradores de fuerza de trabajo.

\subsection{Cuando tenga la tierra}

El reclamo de políticas de acceso a la tierra por parte de los asalariados nucleados en la UTAA responde a la necesidad de superar una forma de subsunción (real) en el capital altamente precaria, caracterizada por bajos niveles salariales, que los coloca en condiciones de pobreza e insatisfacción de necesidades básicas, alta zafralidad, en tanto solo tienen trabajo estable durante la cosecha de caña (junio a octubre); alta penosidad, en tanto se trata de un trabajo fatigante en extremo, y subordinación respecto de los empresarios cañeros.

En este plano, el acceso a la tierra implicó objetivamente la superación, al menos parcial, de las condiciones de trabajo típicas de los asalariados rurales de la caña, ya que generó una inserción laboral estable, mejor remunerada y de menor penosidad. La mejora en la calidad de vida tiene que ver directamente con el incremento de los ingresos. Comparado con el trabajo asalariado para una misma zafra, mientras que en el año 2012 la remuneración por cortar caña -a un promedio de 2,5 toneladas por día- generaba un ingreso mensual líquido de $\$ 11.100$ pesos uruguayos desde junio a octubre (5 meses), un colono promedio en la Sendic obtenía $\$ 15.000$ pesos uruguayos por mes todo el año por concepto de mantenimiento (pagado por ALUR), más un posible ingreso extra en función del resultado productivo. Esta cifra en las primeras zafras superó los $\$ 100.000$ pesos uruguayos por colono por año. La mejora en los ingresos permitió elevar sus niveles de consumo -accedieron a bienes que antes estaban fuera de sus posibilidades-, mejoraron su alimentación, su vivienda y adquirieron medios de transporte para sus familias.

Otro aspecto objetivable, y que es valorado por los colonos, es el incremento en el nivel de autogestión, de toma de decisiones y manejo del tiempo personal, en comparación con el trabajo asalariado. En la CRSA son ellos los que toman parte de las decisiones productivas, regulan sus tiempos y su rutina. En lo referido a la división social del trabajo, la concepción de las tareas productivas resultó de la negociación entre los técnicos de ALUR y cada grupo, en una ecuación en la que tendió a primar el saber técnico por sobre la opinión de los trabajadores. Por su parte, la ejecución de las tareas recayó en diversos agentes. El trabajo mecanizado fue asumido por los colonos, en el caso de que poseyeran la maquinaria correspondiente, y en el caso contrario se tercerizaron las tareas con empresas de servicios, entre otras ALUR. El trabajo manual lo realizan mayormente trabajadores asalariados, bajo la dirección de los colonos, aunque hay casos puntuales en los que éstos colaboran con la tarea. En el caso particular de Peludos del Norte 2, en 2012 durante el corte de caña la relación asalariados/colonos fue de 8 a 1, mientras que el resto del año la relación fue de 4-5 a 1, lo que evidencia el alto uso de trabajo asalariado en todo el proceso productivo. Por último, las tareas relacionadas con la gestión (registro, pago de salarios, balances anuales, abastecimiento de insumos) son asumidas por los colonos, salvo la liquidación de sueldos que se terceriza en estudios contables.

La división del trabajo en el interior de los grupos tiende a mantenerse a lo largo del tiempo, no obstante lo cual han ido rotando en las tareas, así como también tienen acuerdo de complementar o cubrir a un compañero del grupo de ser necesario. Esta flexibilidad y rotación en el proceso de trabajo es una novedad altamente valorada, ya que como asalariados estaban restringidos casi exclusivamente a las tareas manuales (corte, riego, aplicación de herbicidas, etc.). 
Otro de los aspectos que se modificó radicalmente fue la rutina de trabajo. De una rutina pautada anualmente por el ciclo del cultivo, y que durante los momentos de zafra implicaba como máximo una jornada de 8 horas de trabajo -saliendo del pueblo a las 6 de la mañana y regresando entre las 14 y las 16- pasaron a una rutina más variable día a día, con jornadas que a veces superan las 12 horas de trabajo, a lo que se suma la necesidad de pernoctar en el campo de forma rotativa. Como contrapartida, el nuevo ritmo de trabajo es más flexible, y permite, según la etapa del cultivo, períodos de vacaciones rotativas entre los integrantes del grupo (fundamentalmente en la prezafra) y, en caso de necesidad y en acuerdo con el grupo, la posibilidad de faltar sin que haya repercusiones en sus ingresos. La contracara de este proceso es la mayor ausencia en el hogar (Íngold, 2014).

Esta última situación está altamente condicionada por la no radicación en la CRSA, que configura en los hechos la separación entre la unidad productiva y reproductiva de las familias. Esto se explica por la falta de condiciones habitacionales y de servicios para el conjunto de las familias, así como porque la distancia entre el predio y los hogares de los colonos posibilita el traslado diario al campo, que ocupa aproximadamente dos horas por día. Asimismo, esta separación entre unidad reproductiva y productiva responde a que buena parte de los colonos prefiere mantener separado el espacio de trabajo del de reproducción, y/o porque parte de la familia no tiene voluntad de dejar sus espacios de vida y socialización.

\subsection{Nuevas subordinaciones}

Los nuevos colonos se insertan en el complejo sucroalcoholero como proveedores de caña de azúcar financiados por ALUR en su estrategia de monopolización del territorio (Echeverriborda et al., 2014). Esta inserción supuso objetivamente un cambio en la modalidad de subsunción del trabajo en el capital. De relaciones salariales (subsunción real) pasaron, gracias al acceso a parte de los medios de producción, a autogestionar parcialmente su trabajo. Sin embargo, la nueva situación supone un nuevo tipo de subordinación, caracterizada por la subsunción híbrida del trabajo en el capital (Foladori, 1986; Marx, 2012), en la que el trabajo de los colonos es subordinado, indirectamente, al capital industrial representado por ALUR. Esta nueva forma de subsunción se produce porque la industria pauta los procesos y tiempos productivos, define el precio de la caña y el paquete tecnológico, supervisa la ejecución de las tareas, financia la producción, el trabajo de los colonos y los jornales de los asalariados. El acceso a la tierra empalma con la estrategia de monopolización del territorio, generando para los colonos una forma de subsunción del trabajo, ya no mediada por el salario, sino por la mercancía caña de azúcar.

Son varios los aspectos que determinan la subordinación al ingenio. En primer lugar, la especialización en la producción de caña de azúcar debido a que la CRSA fue creada para producir caña para ALUR. Al ingresar a la Colonia, los colonos firmaron un contrato con el INC que los compromete a producir caña, y con ALUR para producir y vender caña al ingenio a cambio de financiamiento y asistencia técnica. A la especialización en la caña se le suman las dificultades para desarrollar proyectos de diversificación por la falta de financiamiento y de fuerza de trabajo familiar radicada en la Colonia.

La dependencia también se refuerza porque todos los colonos perciben el "mantenimiento" mensual por parte de ALUR, que a mediados de 2012 era de 15.000 pesos uruguayos por mes. El mantenimiento es un adelanto por concepto de su trabajo que luego se cobra con intereses al rendir el balance de la zafra, y que por la vía de los hechos oficia como un salario, aunque sea un préstamo, ya que permite que los colonos tengan un ingreso mensual asegurado todo el año, hecho que garantiza su reproducción material y por ende su compromiso laboral con la producción de caña. El mantenimiento condensa en sí la contradicción entre la generación de autonomía y la dependencia con el ingenio, ya que, mientras garantiza un ingreso mensual para la reproducción de los colonos y sus familias, al mismo tiempo también garantiza su dependencia con la empresa ya que no les sería posible mantenerse todo el año sin este aporte. También la dependencia es reforzada por la deuda que asumieron al ingresar a la CRSA con el INC y ALUR por concepto de la caña 
implantada, y por la posibilidad de quedar endeudados con el ingenio en caso de obtener malos resultados económico-productivos.

El aspecto que con mayor claridad expresa la subordinación de los colonos es el margen de toma de decisiones que tienen para autogestionar el proceso productivo. Esta situación también es contradictoria, porque al tiempo que siendo colonos logran mayores niveles de autogestión que como asalariados, esto no significa que efectivamente controlen el proceso productivo. Al respecto, es importante identificar los niveles de toma de decisiones en que participan los colonos. En lo que refiere a la ejecución táctica de las tareas, los colonos tienen importantes niveles de control, deciden si aplicar herbicida de día o de noche, por dónde comenzar el corte de caña, etc. Sin embargo, las decisiones estratégicas que afectan la producción, vinculadas al mantenimiento del cultivo, a la organización de la cosecha, a las variedades a sembrar no son resorte de los colonos, sino de la empresa, que a través de sus técnicos de campo indica qué hacer.

Para operacionalizar esta subordinación son claves los técnicos agrícolas de ALUR, que ofician como el agente de mediación entre la empresa y los grupos, y que, muchas veces gracias al vínculo de confianza y respeto que tienen los colonos por el saber técnico, facilitan su trabajo. Uno de los técnicos de campo de ALUR manifestó con claridad su tarea:

mi función básicamente es productiva, yo lo que trato es que ellos... que ALUR el dinero que esté invirtiendo en ellos, provoque una... haya un resultado productivo (...) es que yo no dejo, por ejemplo, que lo hagan cuando... yo digo hay que hacerlo esta semana, esta semana quiero que lo hagan, porque entiendo que es el momento (...) alguien la tiene que hacer; o la hacen ellos o la hacemos nosotros, pero lo que no puede pasar es que dejemos perder esa hectárea de caña (...) o sea, no, esas cosas hay que hacerlas, sí o sí hay que hacerlas.

Porque además el técnico de campo, como mediador entre la empresa y los colonos, es evaluado por el resultado productivo

El ingenio es así la figura omnipresente en todo el proceso productivo de la caña de azúcar y en la organización general del trabajo, al punto que todos los colonos reconocen que sin este la CRSA no produce más caña. De esta forma, ALUR es al mismo tiempo la empresa que los subordina y que los viabiliza, o si se quiere, que los viabiliza subordinadamente, al punto que se puede sostener la tesis de que sin ALUR la CRSA nunca hubiera existido, ni en su origen ni en su desarrollo ulterior. Es por eso que todos los colonos reconocen la importancia y la relevancia que tiene la empresa para el funcionamiento de su emprendimiento productivo más allá de su lógica empresarial, ya que en definitiva fue la que les permitió dejar de ser asalariados y volverse productores directos (aunque sean subordinados).

En una situación diferente a la de ALUR aparece el INC, que oficia como el terrateniente del proceso productivo en tanto se apropia de plusvalor bajo la forma de renta del suelo, que canaliza para la adquisición de nuevas tierras. Su presencia en la Colonia tiene dos expresiones claras, una más fiscalizadora, que recae en la Gerencia Regional que controla el cobro de las rentas (subsidiadas con respecto al precio de mercado) y el cumplimiento de la Ley de Colonización, y otra más promotora, que recae en la Gerencia de Procesos Asociativos y que, entre otras tareas, tiene a su cargo el fortalecimiento de los grupos de la CRSA.

Los colonos le reclaman al INC mayor participación y apoyo, al tiempo que le critican que "solo aparece para cobrar", y que prolongó por la vía de los hechos el comodato precario más allá de los dos años iniciales. Es indudable que, luego de entregada la tierra, la mayor dependencia de los colonos es con ALUR y no con el INC, ya que éste incide muy poco en los procesos productivos, los colonos tienden a ver mejor el rol de ALUR en tanto está presente con apoyos concretos mientras que el INC sólo se interesa por cobrar la renta y fiscalizar el funcionamiento grupal. Sin embargo, y más allá de la apreciación que tienen los colonos del Instituto, este tiene un alto interés en el éxito de la CRSA como proyecto socioproductivo, no solo como proveedor de materia prima para ALUR, sino como espacio de "experimentación social" en el que colectivos de asalariados rurales mejoran sus condiciones de vida a través del trabajo colectivo.

Un último actor a destacar, que oficia a la vez como rentista y prestador de servicios, y que tiene un peso determinante en la estructura de costos, es el sistema de riego de CALPICA (Cooperativa Agropecuaria 
Limitada de Producción e Industrialización de la Caña de Azúcar). Su presencia es mucho menos visible que la de ALUR y el INC, no obstante lo cual su condición de proveedor exclusivo de agua en dicha zona le permite cobrar precios monopólicos, por encima de su precio de producción, con los cuales se apropian de una masa creciente de plusvalor. Para tener una referencia, en el verano de 2010, cuando las lluvias hicieron prácticamente innecesaria la utilización del sistema de riego, el costo del mismo alcanzó los US\$300/ha, cuando la renta del suelo ese año estaba por debajo de los US\$100/ha.

\subsection{Autonomias posibles}

En este escenario general de subordinación es pertinente abordar los márgenes de acción de los nuevos colonos. Una forma de hacerlo es comparar su situación con otros grupos de la CRSA y, en particular, con el caso de "Campo Placeres", la primer experiencia de acceso a la tierra en el marco del proyecto sucroalcoholero.

En la CRSA las condiciones de acceso a la tierra fueron prácticamente las mismas para todos los grupos, lo que hace que los niveles de subordinación al ingenio sean muy similares. No obstante, como surge del estudio de Moraes (2014) sobre los diferentes grupos de la CRSA, es posible identificar grupos que, al lograr buenos resultados económico-productivos e invertir en maquinaria, incrementaron sus niveles de autogestión al depender menos del ingenio y/o de prestadores de servicios de maquinaria. Mientras, otros grupos por conflictos internos y magros resultados económicos tendieron a delegar tareas en ALUR, lo que decantó en un espiral de subordinación con el ingenio que los dejó más cerca de la condición de proletarios con tierra. En este escenario, Peludos del Norte 2 es uno de los grupos que logró un proceso de incipiente acumulación e incremento de autonomía, mientras que Peludos del Norte 1 venía por una senda similar hasta la subdivisión de comienzos de 2012, que los llevó a una etapa de incertidumbre.

El otro caso paradigmático de comparación es la experiencia de los asalariados pertenecientes a la UTAA que ingresaron a "Campo Placeres". Moraes (2012) evidencia cómo los trabajadores de esta experiencia quedaron totalmente subordinados a ALUR que, además, en este caso ofició de subarrendatario de parcelas de 10 hectáreas por adjudicatario. En la CRSA los colonos tienen la posibilidad de ser adjudicatarios de la tierra e iniciar un proceso de radicación con seguridad en la tenencia de la tierra, perciben todo el año una mayor partida por concepto de mantenimiento, han invertido en maquinaria y han controlado los niveles de endeudamiento, mientras que en "Campo Placeres" la tenencia de la tierra es sumamente precaria (por sólo 10 años), no tienen acceso ni a maquinaria ni al crédito, el mantenimiento es más bajo y es zafral, y los niveles de deuda son prácticamente incobrables.

El contraste entre las experiencias es ejemplificador, ya que muestra que más allá de un escenario general de subordinación al ingenio, fruto de su estrategia de monopolización del territorio, es posible generar márgenes de autonomía si están dadas las condiciones objetivas (superficie, acceso a crédito y maquinaria) y subjetivas (unidad y cohesión del grupo).

\subsection{Nuevospatronos}

El acceso a la tierra para los colonos no contiene como único movimiento el cambio de subsunción en el capital, ya que la gestión de los medios de producción abre otra posibilidad en la sociedad capitalista: la compra de fuerza de trabajo. En el caso de Peludos del Norte, pero es una tendencia generalizada en toda la CRSA, esta posibilidad se volvió realidad en la medida que los colonos utilizan fuerza de trabajo asalariada en prácticamente todas las fases del proceso productivo, sobre todo durante la cosecha, el riego, la aplicación de herbicidas y fertilizantes. En Peludos del Norte 2 la relación asalariados/colonos fue, durante 2012, de 8 a 1 durante la cosecha de la caña y de 4-5 a 1 el resto del año. Por su parte, en Peludos del Norte 1, durante toda la zafra 2011 pasaron por el grupo de corte entre 80 y 90 trabajadores (no simultáneamente). 
La cosecha de la caña es la tarea donde es más común el uso de trabajo asalariado. Los factores materiales que explican una práctica generalizada en casi toda el área cañera son: la necesidad objetiva de trabajo concentrado en el tiempo de zafra, y la disponibilidad de fuerza de trabajo barata para realizar la tarea, lo que vuelve posible evitar una tarea agobiante y degradante físicamente que supone cortar y trasladar en el hombro más de 2,5 toneladas de caña de azúcar por día. A estos, se suma la legitimación ideológica de que el corte de caña se realiza con trabajo asalariado.

En otras tareas, como el riego, el control de herbicidas y la fertilización, también aparece la necesidad de fuerza de trabajo extragrupal, así como incide la mayor eficiencia del trabajo manual en algunas tareas. Sin embargo la generalización del trabajo asalariado no responde sólo al déficit estacional de trabajo, sino a la posibilidad objetiva de consumir menos su propia fuerza de trabajo.

Prácticamente todos los entrevistados reconocen que el trabajo asalariado es una necesidad, en tanto en los picos de demanda de fuerza de trabajo no dan abasto, por lo que varía su opinión ante esta situación. Mientras algunos colonos lo ven como algo positivo porque ayudan a otro trabajador que precisa ingresos, otros identifican una contradicción en usar asalariados y no ser todos socios o familiares. La elección de los asalariados a contratar sigue un patrón en el que la primera prioridad la tienen los familiares (hijos, hermanos, cuñados), y luego conocidos y/o trabajadores del sindicato que estén desempleados.

Los colonos coinciden que la relación con sus asalariados es muy buena, sin problemas, ya que cumplen el convenio y son "uno más". A esto se deberían agregar las relaciones de parentesco que en cierto sentido encubren una relación de explotación que no desaparece aunque se trate de un familiar, ya que no está planteada ni la socialización de los ingresos de la producción entre los asalariados ni su incorporación como socios estables a los grupos.

El uso de trabajo asalariado impone nuevas preocupaciones como la dificultad para conseguir trabajadores eficientes y comprometidos con el proceso de trabajo, problema parcialmente resuelto a partir de la forma de selección de los asalariados (familiar, amigo, vecino); no obstante los colonos sostienen que cada vez más se les dificulta conseguir buenos trabajadores. Ante esta dificultad es que aparece como alternativa la mecanización del corte de caña, que comenzó a viabilizarse con la compra de tres cortadoras de caña a granel por parte de ALUR, lo que permitiría cubrir el déficit de fuerza de trabajo y reducir costos.

La función como patrones los coloca en un nuevo rol en el proceso de trabajo que los diferencia de los asalariados, ya que deben velar por la maximización en el uso de la fuerza de trabajo comprada asumiendo el rol de capataces. Sin embargo, éste no es el único factor de diferenciación. A diferencia de los asalariados, ahora los colonos tienen mejores ingresos y han accedido a medios de producción y consumo vedados a los primeros -cuyo caso paradigmático son los vehículos-. El nuevo estatus se observa también en otras prácticas cotidianas como la selección de los lugares para almorzar o la comida que consumen.

Todos estos aspectos están relacionados con el hecho de que ahora los colonos son apropiadores de plusvalor. Plusvalor que no necesariamente retendrán para iniciar un proceso de acumulación, ya que, como se vio, la subordinación al ingenio dificulta su apropiación. Esta situación los coloca como intermediarios entre el capital (ALUR) y la fuerza de trabajo (asalariados), en tanto garantizan el proceso de explotación del trabajo que valoriza el capital. Los colonos experimentan esta situación y son conscientes de que un mayor costo de la fuerza de trabajo reduce sus ganancias de igual modo que un trabajo mal hecho o poco productivo. Se quejan del poco compromiso de los asalariados en tanto ya no hay trabajadores como "los de antes", aquellos que trabajaban de sol a sol, cortaban bien la caña y aguantaban toda la zafra. Tampoco aparece como posibilidad modificar la forma de remunerar la fuerza de trabajo.

\section{3. ¿Yo SÉ QUIÉN SOY?}

El recorrido realizado hasta aquí sobre las transformaciones y las nuevas contradicciones por las que han pasado los colonos permite responder las principales preguntas que orientaron esta investigación. 


\subsection{Clase, en transición}

Los trabajadores de Peludos del Norte experimentan dos movimientos simultáneos, en parte contradictorios entre sí: por un lado, un proceso de viabilización como productores directos subordinados al ingenio en un figura que se asimila a la del "proletario con tierras" (Foladori, 1986) por los niveles de subsunción híbrida en el capital; y por otro lado, se consolidan como una figura intermediaria entre el capital industrial y la fuerza de trabajo, que garantiza la apropiación de plusvalor en una figura símil a la del capataz, en la medida en que se apropian pero no retienen plusvalor.

La síntesis de estos dos movimientos es una figura híbrida, inestable y tendencialmente transicional, en la medida en que, o podrán iniciar un proceso de acumulación a partir de la explotación virtuosa de la fuerza de trabajo que les permita crecer en área, medios de producción y trabajo asalariado, o podrá iniciar un proceso de creciente subordinación al ingenio que los consolide como proletarios con tierra que paulatinamente delegan tareas en otros agentes, como ha sucedido en el caso de "Campo Placeres" (Moraes, 2012).

Esta clase combina la condición del productor mercantil directo que utiliza su fuerza de trabajo e intenta retener la mayor parte del valor que genera, y la condición de capitalista que se apropia de plusvalor generado por el trabajo asalariado, sea extendiendo la jornada laboral, intensificando el proceso productivo o pagando bajos salarios. Hay entonces un cambio de clase para los trabajadores que eran asalariados y ahora ocupan esta figura híbrida que los ubica en una posición intermedia y transicional entre las clases polares del modo de producción capitalista. Este cambio de clase se produce por la combinación de una serie de factores.

En primer lugar es posible por la estrategia de monopolización del territorio de ALUR que genera condiciones para la reproducción de relaciones de producción no-capitalistas que, a través de mecanismos híbridos de subsunción del trabajo en el capital, funcionalizan a los proveedores de caña de azúcar al proceso de valorización. Segundo, la reactivación del INC, que comenzó a comprar y entregar tierras para viabilizar el proyecto sucroalcoholero. Se trata de dos políticas promovidas por el Estado que se complementan en el territorio de la Colonia Sendic, y que son resultado de la etapa inaugurada con la llegada al gobierno del FA. Sin embargo, son dos políticas con lógicas diferentes: mientras el objetivo de ALUR es netamente empresarial, el INC aparece como el socio terrateniente pero sin una racionalidad capitalista, en tanto sus objetivos incluyen generar condiciones que habiliten la reproducción social de trabajadores a partir del acceso a la tierra.

No obstante, la CRSA no se hubiera configurado tal como es sin el proceso de movilización de los trabajadores rurales, con especial protagonismo de la UTAA que, fruto de una correlación de fuerzas favorable, consiguió la asignación directa de tierra para sus trabajadores. Aunque no se puede afirmar que fue la movilización de la UTAA la que provocó la creación de la Colonia, es indudable que ésta sí determinó que buena parte de los nuevos colonos fueran seleccionados directamente por las organizaciones de trabajadores de Bella Unión.

De esta forma confluyen en la CRSA los intereses objetivos de trabajadores que quieren convertirse en productores directos pero no tienen medios de producción para iniciar el proceso productivo, y de ALUR, que precisa de productores especializados en la caña de azúcar, para lo cual financia todo el proceso productivo. Esto genera una situación de reciprocidad contradictoria en la medida que los colonos precisan de ALUR para producir, ya que sin ese apoyo no podrían ni desarrollar el proceso productivo en su totalidad ni sobrevivir de la producción de caña de azúcar, al tiempo que el ingenio precisa de los colonos como fuente de materia prima. La contradicción aparece porque así como ALUR es imprescindible para viabilizar la CRSA, al mismo tiempo cuestiona la apuesta de generar colectivos de trabajadores autogestionados. Por eso la dependencia con la industria puede al mismo tiempo ser tanto una limitante para el desarrollo autónomo de los grupos como una oportunidad para su dinamización.

Para ALUR la viabilización de relaciones de producción no-capitalistas, a diferencia de la relación típicamente capitalista, aparece en este caso como una ventaja en la medida en que los colonos tienen mayor 
compromiso y responsabilidad con la producción pues de ésta dependen sus ingresos, y para ello adaptan sus tiempos de vida a los tiempos de la producción, lidiando así con la división temporal del trabajo que imponen los ciclos biológicos al desarrollo del capitalismo en el campo. Se está entonces ante un caso en el que, al decir de Kaustky (1986), el capital reproduce al productor directo o, al decir de Oliveira (2004), el capital reproduce relaciones de producción no-capitalistas cuando monopoliza el territorio.

Parecería que esta confluencia de intereses podría configurar un proceso típico de recreación campesina (Paulino, 2006), es decir, de producción de nuevos productores familiares subsumidos al capital. Sin embargo, las características específicas de la forma de colonización de la CRSA truncan esta posibilidad, generando la figura híbrida antes conceptualizada, que poco tiene en común con el productor familiar típico y que, parafraseando a Shanin (1988), se parece más a un obrero especializado de una línea de montaje que a un campesino.

Los factores que truncan este proceso tienen que ver por un lado con la ausencia de trabajo familiar en todo el proceso productivo, en la medida en que los que aportan fuerza de trabajo propia son únicamente los colonos titulares, dado que los familiares que trabajan en la Colonia lo hacen como asalariados, no como fuerza de trabajo familiar. Es evidente que el proceso de producción de caña de azúcar en la CRSA no requiere del trabajo familiar, en tanto se viabiliza a partir del trabajo de colonos, asalariados y técnicos agrícolas, así como el proyecto colonizador del INC, dirigido a la producción de caña de azúcar para ALUR, tampoco requiere familias radicadas en el campo.

Esta particularidad aleja a los colonos de las características típicas de la producción familiar donde coexisten unidad productiva y reproductiva, y donde adquiere centralidad el trabajo familiar como rasgo específico; y, por el contrario, los acerca a las condiciones típicas del trabajo asalariado donde el espacio de reproducción está separado del espacio productivo.

El otro movimiento que define a este nuevo sujeto y que a la vez trunca el proceso de recreación de productores mercantiles con trabajo familiar es su consolidación como intermediario entre el capital industrial y la fuerza de trabajo, en la medida en que compra fuerza de trabajo financiado por ALUR, y supervisa y controla la ejecución de las tareas buscando la mayor eficiencia posible en la explotación de la fuerza de trabajo, aunque luego tiene dificultades para retener el plusvalor por los niveles de subsunción en el capital. Esto último es lo que objetivamente lo distingue de los empresarios cañeros, que al poseer medios de producción y capital para autofinanciarse tienen condiciones para retener y acumular el plusvalor que apropian en el proceso productivo; de los productores familiares que se basan en el uso de trabajo familiar y no en la generalización del trabajo asalariado; y de los propios asalariados cuya fuerza de trabajo ahora compran.

\subsection{Conciencia de clase, en transición}

El cambio de clase analizado impactó en la autopercepción de los colonos como clase, al punto que se identifica un proceso en transición en el cual coexisten conflictivamente elementos de su conciencia anterior, como asalariados, con elementos relativos a la nueva posición de clase. Esta tensión da cuenta de un proceso en el que la nueva base material determina la conciencia (Marx, 2008).

Los colonos constatan que están ante una nueva situación que deriva del cambio de inserción en el proceso de producción. Reconocen que siguen siendo trabajadores que han accedido a la tierra y que ahora son "dueños" de su trabajo. No obstante, coexiste con lo nuevo la afirmación de su conciencia de asalariados, al punto que para algunos en nada se alteró su identidad: "yo siempre les digo 'yo siempre voy a ser peludo, voy a seguir peludo nomás', un asalariado que tiene la oportunidad de tener un área de caña”.

El aspecto en el que esta tensión entre lo nuevo y lo viejo se hace más evidente es en su definición con respecto a las clases polares del modo de producción, los claramente asalariados y los claramente burgueses. Con respecto a sus excompañeros de clase la tendencia es a negar su rol como patrones, afirmando su condición de iguales: 
Yo para mi sigo siendo lo que era antes, una trabajadora nada más, y mismo el vínculo con los trabajadores, somos uno más, estamos con ellos ahí todo el día, trabajamos con ellos, estamos con ellos. Y no hay esa diferencia, viste (...) tomamos del mismo mate, comemos, a veces hacemos un asado entre nosotros.

Pero esta afirmación que niega la diferencia convive con la aceptación del uso generalizado de trabajo asalariado, que inclusive es presentado como un rasgo positivo en tanto "están generando trabajo".

La forma de lidiar con esta contradicción no es económica, a partir de otras formas de remunerar la fuerza del trabajo por ejemplo, dado que la mayoría de los colonos se oponen al ingreso de nuevos socios a sus grupos porque supondría dividir los ingresos de la producción entre más integrantes, e implicaría poner a los nuevos colonos en pie de igualdad a la hora de organizar colectivamente la producción.

Por el contrario, se enfrentan a la contradicción enunciando una ética según la cual se afirma la igualdad como trabajadores a pesar de los distintos roles, la necesidad de seguir trabajando y de tener otro tipo de vínculo con los asalariados. Esta "ética empresarial" supone que los colonos que compran fuerza de trabajo no son como los empresarios cañeros, y esto es así porque tienen el mismo origen de clase como asalariados:

[los empresarios] vienen de cuna de oro, como quien dice, el peón es una herramienta, los trabajadores para ellos es una herramienta, solo eso. A diferencia de eso, nosotros venimos de ser esa herramienta y no pensamos que el trabajador que vaya a estar con nosotros sea una herramienta, sino que es una persona, que detrás de ella hay una familia y que tiene esa necesidad de trabajar

\subsection{Organización, en transición}

Los cambios de clase y en la conciencia no podían sino afectar su vínculo con sus excompañeros de la UTAA, el espacio donde construyeron su identidad y desde el cual se organizaron para acceder a la tierra. Estos cambios provocan, al igual que en las otras dimensiones analizadas, una situación transicional en la que, al tiempo que se mantiene la fidelidad y la identificación con su organización de origen, los colonos identifican y exploran alternativas de organización para defender sus intereses.

El cambio más claro ha sido su distanciamiento del sindicato, ya que éste organiza y representa a los asalariados que trabajan en la Colonia Sendic, de forma que defiende intereses de clase diferentes a los suyos. Varios colonos manifestaron que ahora no van más al sindicato porque

Los trabajadores asalariados nos discriminan porque hoy tenemos caña (...), es el gran problema que hay entre los trabajadores que no aceptan que un trabajador tenga caña, tenga tierra (...) Delante del sindicato nosotros somos unos patrones, capaz que con los dirigentes de UTAA no tenemos problema, ninguno tenemos problema, es con la base.

No obstante este distanciamiento, siguen afirmando su fidelidad con el sindicato, a la que le deben el ingreso a la Colonia y le reconocen un rol supervisor en el funcionamiento de los grupos que accedieron la tierra. En el mismo sentido, han apoyado la demanda de más tierra para los asalariados y han colaborado en diversas movilizaciones del sindicato, así como defienden la necesidad de juntar a los pequeños productores con el sindicato para fortalecer la lucha por la tierra.

Esta fidelidad con la UTAA no es contradictoria con la necesidad de generar una organización específica de pequeños productores, desde la cual defender sus intereses específicos, ahora marcados por la gestión de un emprendimiento económico. Esta nueva organización se piensa por fuera del sindicato, ya que la UTAA es un sindicato de trabajadores, pero también por fuera de la organización patronal, la Asociación de Plantadores de Caña del Norte Uruguayo (APCANU). El dispositivo organizativo que están construyendo los colonos expresa el cambio de clase que están atravesando, ya que no se reconocen representados ni en la UTAA ni en la APCANU, lo que a su vez es coherente con el esbozo de una nueva conciencia que niega su condición de asalariados y de patrones.

Sin embargo, el distanciamiento entre los colonos y la UTAA no responde sólo a las acciones de los primeros, en la medida que el sindicato es corresponsable de la situación. El sindicato no tiene una estrategia 
deliberada que intente organizar a los trabajadores una vez que entran a la tierra, más allá de las dificultades estructurales que supone contener en una misma organización a compradores y vendedores de la fuerza de trabajo. Parecería que la UTAA disocia la ideación de nuevas relaciones de producción en el campo -con trabajadores afincados en la tierra- de la implementación de dichos proyectos cuando se concretan. Su rol protagónico ha quedado restringido a la etapa de lucha por la tierra, para luego distanciarse paulatinamente de los proyectos productivos.

Este distanciamiento de los emprendimientos productivos puede explicarse, al menos de forma hipotética, porque la pauta central de los casi 1.000 afiliados a la UTAA es estrictamente sindical, es decir, está relacionada con la defensa del salario y las condiciones de trabajo, quedando en segundo lugar la demanda de tierra, lo que ha dificultado organizar a los trabajadores que el sindicato coloca en la tierra. Y esto porque la UTAA es ante todo un sindicato que aglutina asalariados, y no de trabajadores/campesinos sin tierra, como sucede en otros lares de Latinoamérica.

Los dirigentes de UTAA reconocen ese distanciamiento, pero, más que reclamar la organización de los colonos en el sindicato, exigen que no olviden quién "los puso en la tierra", ni pierdan su identidad de clase. Al mismo tiempo reconocen que hay una contradicción en el hecho de que los colonos usen trabajo asalariado, pero que esta "contradicción se da por qué, porque hay algo, si no hubiera nada... no pasaría nada".

\subsection{Diferenciación social en la CRSA}

El último aspecto a abordar refiere a las características específicas del proceso de diferenciación social en la producción de caña de azúcar, que opera como una fuerza centrífuga que impide la consolidación del productor directo de mercancías con base en el trabajo familiar. Estos rasgos específicos determinan la condición transicional, tanto de la posición como de la conciencia de clase, en la medida en que la inserción de los nuevos colonos en la fase primaria del complejo sucroalcoholero es inherentemente inestable y, por tanto, o devendrá en un proceso de incipiente acumulación que los consolide como intermediarios entre el capital y el trabajo asalariado, o en un proceso de creciente subordinación, a través de mecanismos híbridos de subsunción en el capital que, de forma tendencial, generen un proletario con tierras.

De esta forma la CRSA no genera sino que impide un proceso de recreación de productores mercantiles, en la medida que reproduce la clase híbrida antes analizada. El caso analizado muestra diferencias con la experiencia colonizadora de "Campo Placeres" que, a juicio de Moraes (2012), produjo proletarios con tierra, un continuo trabajador-asalariado-subarrendatario que no está siquiera en un proceso de reproducción simple.

En este sentido, el acceso a la tierra en el marco del proyecto sucroalcoholero se muestra en primera instancia como contratendencial al proceso de diferenciación social típico de las economías capitalistas, en la medida en que los que fueron diferenciados como asalariados tienen la posibilidad de recuperar medios de producción. Sin embargo, esta recuperación es viabilizada como parte de la reproducción capitalista de la relación no-capitalista, e inmediatamente los nuevos colonos se ven enfrentados a la obstinada tendencia a la diferenciación social (Foladori, 1986) que impide su consolidación como productores de mercancías, en la medida en que o los diferencia hacia arriba acumulando capital, o los diferencia hacia abajo subordinándolos totalmente al capital.

\section{Conclusiones}

La investigación identificó que los nuevos colonos dejaron de vender su fuerza de trabajo para pasar a autogestionar parte de los medios de producción, lo que provocó un cambio de clase que resulta del pasaje de la forma real de subsunción en el capital a formas de subsunción híbrida, fruto de la estrategia de 
monopolización del territorio de ALUR. La estrategia del ingenio, junto al rol terrateniente del INC, viabiliza subordinadamente relaciones de producción no-capitalistas funcionales al proceso de valorización del capital, en un formato específico que no requiere de trabajo familiar ni de la radicación de las familias en el campo. Sin embargo, este cambio no sólo incluye una nueva forma de subsunción en el capital, sino que además coloca a los colonos como intermediarios entre el capital y la fuerza de trabajo, en una figura tipo capataz donde supervisan y garantizan la explotación de la fuerza de trabajo que compran financiados por ALUR.

De ambos movimientos surge una clase híbrida, transicional e inestable, que contiene elementos del productor directo de mercancías subsumido en el capital con elementos capitalistas, en tanto apropiadores de plusvalor que, sin embargo, difícilmente retienen por los mecanismos de subsunción.

Este cambio en las relaciones sociales de producción provoca cambios en su autopercepción como clase, que ahora contiene elementos de su vieja conciencia como asalariados, con elementos relacionados con su nueva inserción en el proceso de producción. En esta nueva conciencia de clase aparece la legitimación de la explotación de la fuerza de trabajo a partir de una ética que los iguala a los asalariados por su origen de clase y, al mismo tiempo, los diferencia de los empresarios cañeros. Esta conciencia es transicional, en tanto está en proceso de transformación, mientras se adapta a la nueva posición económica de los colonos sin terminar de renegar de su vieja conciencia como asalariados.

La condición transicional de ambos procesos se explica por las características específicas del proceso de diferenciación social en la fase primaria del complejo sucroalcoholero que impiden la consolidación de los colonos como productores mercantiles, en la medida en que o los diferencia hacia arriba acumulando capital generalizando el trabajo asalariado, o los diferencia hacia abajo subordinándolos totalmente al capital. De esta forma, el acceso a la tierra en el marco del proyecto sucroalcoholero es plenamente funcional al proceso de valorización de capital y no logra instituir un proceso contratendencial al proceso de diferenciación social típico de las economías capitalistas.

\section{ReFERENCIAS}

Buxedas, M. (1984). Enfoques para el análisis: el sistema agropecuario y los complejos agroindustriales. En CIEDUR (Ed.), La cuestión agraria en el Uruguay (pp. 25-37). Montevideo: Fundación de Cultura Universitaria.

Chiappe, M., y Espasandín, N. (Eds.) (2014). Acceso a la tierra en cuestión: dependencia y autonomía en la Colonia Raúl Sendic Antonaccio en Bella Unión. Montevideo: Letraeñe.

Echeverriborda, M., Espasandín, N., Íngold, M., Moraes, Á., Otero, M., y Oyhantçabal, G. (2014). El complejo sucroalcoholero. En M. Chiappe y N. Espasandín (Eds.), Acceso a la tierra en cuestión: dependencia y autonomía en la Colonia Raúl Sendic Antonaccio en Bella Unión (pp. 57-83). Montevideo: Letraeñe.

Foladori, G. (1986). Proletarios y campesinos. México: Universidad Veracruzana.

Hocsman, L. D. (2003). Reproducción social campesina. Tierra, trabajo y parentesco en el chaco árido serrano. Argentina: Centro de Estudios Avanzados - Universidad Nacional de Córdoba.

Íngold, M. (2014). Género y generaciones. En M. Chiappe y N. Espasandín (Eds.), Acceso a la tierra en cuestión: dependencia y autonomía en la Colonia Raúl Sendic Antonaccio en Bella Unión (pp. 170-194). Montevideo: Letraeñe.

Instituto Nacional de Colonización (INC). (2009). Informe de la Regional Artigas del Instituto Nacional de Colonización. Artigas. Inédito.

Instituto Nacional de Colonización (INC). Actas directorio 2008-2013. Recuperado de http://www.colonizacion.co m.uy/content/view/975/165/

Kaustky, K. (1986) [1899]. A questâo agrária. Sâo Paulo: Nova Cultural.

Marx, K. (2008) [1859]. Contribución a la crítica de la economía política. México DF: Siglo XXI.

Marx, K. (2010) [1872]. El capital: El proceso de producción del capital. Tomo I. Buenos Aires: Siglo XXI. 
Marx, K. (2012). El capital: Tomo I Capitulo VI (inédito). Resultado del proceso inmediato deproducción. Rosario: Puño y Letra.

Merenson, S. (2016). Los peludos. Cultura, politica y nación en los márgenes del Uruguay. Buenos Aires: Gorla.

Moraes, A. (2012). ¿Campo en disputa? Estudio de la experiencia de los trabajadores de UTAA en el campo de Placeres del proyecto sucroalcoholero (Tesis Ingeniero Agrónomo). Universidad de la República. Facultad de Agronomía Montevideo, Uruguay). Recuperada de http://biblioteca.fagro.edu.uy/cgi-bin/wxis.exe/iah/?IsisScript=iah/iah $. x i c \& l a n g=E \& b a s e=T E S I S$

Moraes, A. (2014). Tierra para el que la trabaja: Conflictos entre lo individual y lo colectivo. En M. Chiappe y N. Espasandín (Eds.), Acceso a la tierra en cuestión: dependencia y autonomía en la Colonia Raúl Sendic Antonaccio en Bella Unión (pp. 124-145). Montevideo: Letraeñe.

Moraes, M. I. (1990). Bella Unión: De la estancia tradicional a la agricultura moderna (1853-1965). Montevideo: Banda Oriental.

Oliveira, A. U. (2004). Geografía agrária: perspectivas no início do Século XXI. Trabajo presentado en II Simposio Nacional de Geografía Agraria. SINGA, San Pablo, Noviembre 2003. Recuperado de http://es.scribd.com/doc /25346227/Perspectivas-Da-Geografia-Agraria-22

Otero, M. (2011). De la luch a a la fábrica. La intervención del Estado en el complejo sucro-alcoholero: una aproximación a los diversos modos de uso de la fuerza de trabajo (Tesis Licenciado en Trabajo social inédita). Universidad de la República. Facultad de Ciencias Sociales, Montevideo, Uruguay.

Oyhantçabal, G. y Carámbula, M. (2011). Lucha por la tierra en el norte de Uruguay. Astrolabio, 7, 284-312.

Panizza, M. (2012). Bella Unión: Luchas sociales en el primer gobierno del Frente Amplio. Período 2005-2010. Montevideo: Extensión Libros.

Paulino, E. T. (2006). Por uma geografia dos camponeses. São Paulo: Editora de UNESP.

Pereira, F. (2011). Tierra: Relaciones entre las organizaciones cañeras y el Estado. La complejidad de una construcción. (Tesis Licenciado en Sociología inédita). Universidad de la República. Facultad de Ciencias Sociales, Montevideo, Uruguay.

Piñeiro, D. y Cardeillac, J. (2014). Producción familiar y agronegocios: dos modelos en conflicto. ALASRU, 10, 187-205.

Sarachu, G., Rossi, V., Echeverriborda, G., Torrelli, M., Riero, A., Riet, J., Gonzales, V., y Bandera, G. (2013). Desarrollo local, encadenamientos y potencial asociativo en Bella Unión: estrategias económico-productivas desde la participación de los trabajadores. Informe final para la CSIC-UdelaR del llamado a Proyectos de vinculación Universidad -Sociedad y Producción (2011-2012). Inédito.

Shanin, T. (1988). Naturaleza y lógica de la economia campesina. Madrid: Anagrama.

Silva, J. E. (2015). Los procesos de subjetivación politica de la Unión de Trabajadores Azucareros de Artigas. (Tesis Magíster en Ciencias Agrarias Inédita) Universidad de la República. Facultad de Agronomía, Montevideo, Uruguay.

Toledo, M. (2011). Relevamiento Colonia Raúl Sendic Antonaccio. Uruguay: Instituto Nacional de Colonización. Inédito.

Toledo, M. (2014). Nuevas políticas de colonización y trabajo asociativo. (Tesis de Maestría en Sociología inédita). Universidad de la República. Facultad de Ciencias Sociales, Montevideo, Uruguay.

\section{Notas}

1 La exposición de las formas de subsunción se encuentran en varios pasajes de la obra de Marx, aunque destacan en particular el capítulo XIV del Tomo I de El capital (Marx, 2010) donde expone someramente las características centrales de las tres formas de subsunción: formal, real e híbrida; y el Capítulo VI Inédito (Marx, 2012). Muy someramente, la subsunción formal refiere a aquella forma en la cual el capital se apropia del proceso de producción precapitalista tal cual estaba, pero lo organiza de forma capitalista (con trabajo asalariado). La subsunción real refiere a lo que Marx llama el modo de producción específicamente capitalista, en tanto es la forma en la cual se revolucionan las condiciones de 
producción dadas las leyes de la competencia, provocando la producción de plusvalía relativa fruto de una "revolución total" en el modo de producción, en la productividad del trabajo y en la relación entre el capitalista y el obrero. Finalmente la subsunción híbrida refiere a aquellas formas en las que al productor se le extrae plusvalor sin que se verifique la subsunción formal (trabajo asalariado), en tanto el capital aún no se apoderó directamente del proceso productivo. Es la forma en la que se subordina, en el momento de la circulación, a los productores directos de mercancías (campesinos, artesanos), en particular por la acción del capital mercantil o usurario. Según Marx (2010) esta es una forma que, de predominar, excluye al modo de producción específicamente capitalista, pero que ha operado históricamente como forma de transición hacia éste, y que incluso es reproducido por el propio capitalismo, como evidencia lo que denomina como industria domiciliaria moderna o patio trasero de la gran industria.

2 "Peludos" es la categoría nativa con la que se reconoce y reconocen los cortadores de caña de azúcar en Uruguay. La misma alude a un animal de la zona (el tatu peludo), y seguramente se empezó a utilizar con el comienzo de la producción de caña de azúcar (década de 1940), aunque según Merenson (2016) muchos trabajadores la identifican con la llegada de Raúl Sendic Antonaccio a la zona a fines de los 50, quien en su condición de procurador y dirigente del Partido Socialista fundó la UTAA (y años después el Movimiento de Liberación Nacional-Tupamaros). 